\title{
INLAND RAIL FREIGHT SERVICES WITH LESS FUEL AND LOWER EMISSIONS
}

\author{
FRANS BAL ${ }^{1} \&$ JAAP VLEUGEL ${ }^{2}$ \\ ${ }^{1}$ University of Applied Sciences, Utrecht, The Netherlands. \\ ${ }^{2}$ Delft University of Technology, The Netherlands.
}

\begin{abstract}
Many countries have enhanced their air quality agenda $\left(\mathrm{NO}_{\mathrm{x}}, \mathrm{PM}_{\mathrm{x}}\right.$ etc.) by a climate change agenda $\left(\mathrm{CO}_{2}\right.$ etc.). A direct way to lower these emissions is by using less energy (fuel) per activity. One of these activities is freight transport. Transport from supplier to factory relies on efficient and costeffective means of transport. Road transport (trucking) is usually preferred. But, trucking is still very dependent on fossil fuels. It is also not suitable for bulk transport over longer distances. In areas without suitable waterways, rail is a logical alternative, but is has its own perils. This paper discusses options to make bulk freight services between Germany and France compliant with emission reduction targets. This leads to the main research question: Is it possible to design rail freight routes that reduce fuel use, emissions of $\mathrm{CO}_{2}, \mathrm{NO}_{\mathrm{x}}$ and $\mathrm{PM}_{10}$, while offering competitive transport times? Main rail corridors show signs of congestion and lack of resilience. It is then interesting to research if (dormant) regional/rural, non-electrified, rail tracks could provide capacity and increase resilience of rail services. Such services could also benefit rural economies. A literature study and conversations with a regional expert were used to develop a case study with a rail service using alternative routes. A model was used to estimate the fuel consumption, emissions and trip times of such services. The study indicates that it takes concerted action to achieve the intended goals.

Keywords: cross-border, economics, emissions, Europe, evaluation, Freight transport, logistics, road, rail, policy-making, simulation.
\end{abstract}

\section{INTRODUCTION}

Freight transport is a vital industry. It allows producers of goods to connect to suppliers and (final) consumers of their goods. This activity is growing more or less continuously due to changing demands and opportunities $[1,2]$ :

- A growing world population with an increasing demand for goods;

- A rising average household income, more disposable income and again a rising demand for goods;

- A demand for more diverse and year round availability of goods, which fuels imports from all over the world;

- Producers aiming to optimise cost of production and inventory, which leads to more reliance on just-in-time availability. Stocks are minimized. This means more frequent and smaller shipments. Loading units like containers are less full, while transport vehicles have a lower loading factor and run partially empty, hence more vehicles are needed;

- Cost minimisation also stimulates the creation of supply chains within larger and more complex trade networks. This means more transport over longer distances and resilience risks;

- Both consumers and produces have a preference for short delivery times, which increases demand for rapid, energy-intensive means of transport, in particular air freight and road transport. 


\subsection{Externalities and policy-making}

More freight transport goes along with an increasing fuel consumption and emissions (Fig. 1). Road transport has the largest modal share. As a consequence, it dominates in both areas.

This research involves countries in the European Union (EU) and their options to reduce the $\mathrm{CO}_{2}$-emissions of freight transport. Its main policy unit, the European Commission, announced an ambitious target of $-60 \% \mathrm{CO}_{2}$ for the year 2050 compared to base year 1990 , and lower thereafter. Freight transport should achieve these policy targets by a major modal shift from road to rail and inland waterways, and a transition to non-fossil fuels [3].

\subsection{Research goal and scope}

Rail freight services are well established for medium to longer distances (500 kms and more). They are rarer over shorter distances. Where they exist, they often have to compete with trucking. This paper is about improvements of (existing) bulk train services. It was estimated what the impact of different routes for these services would be in terms of fuel consumption and emissions of $\mathrm{CO}_{2}, \mathrm{NO}_{\mathrm{x}}$ and $\mathrm{PM}_{\mathrm{x}}$. This continuation of earlier research [4] integrates the following topics:

- Freight transport and climate change [5] - quantitatively;

- (Re)routing of freight traffic [6] - quantitatively;

- Regional-economic impact of freight transport [7] - qualitatively.

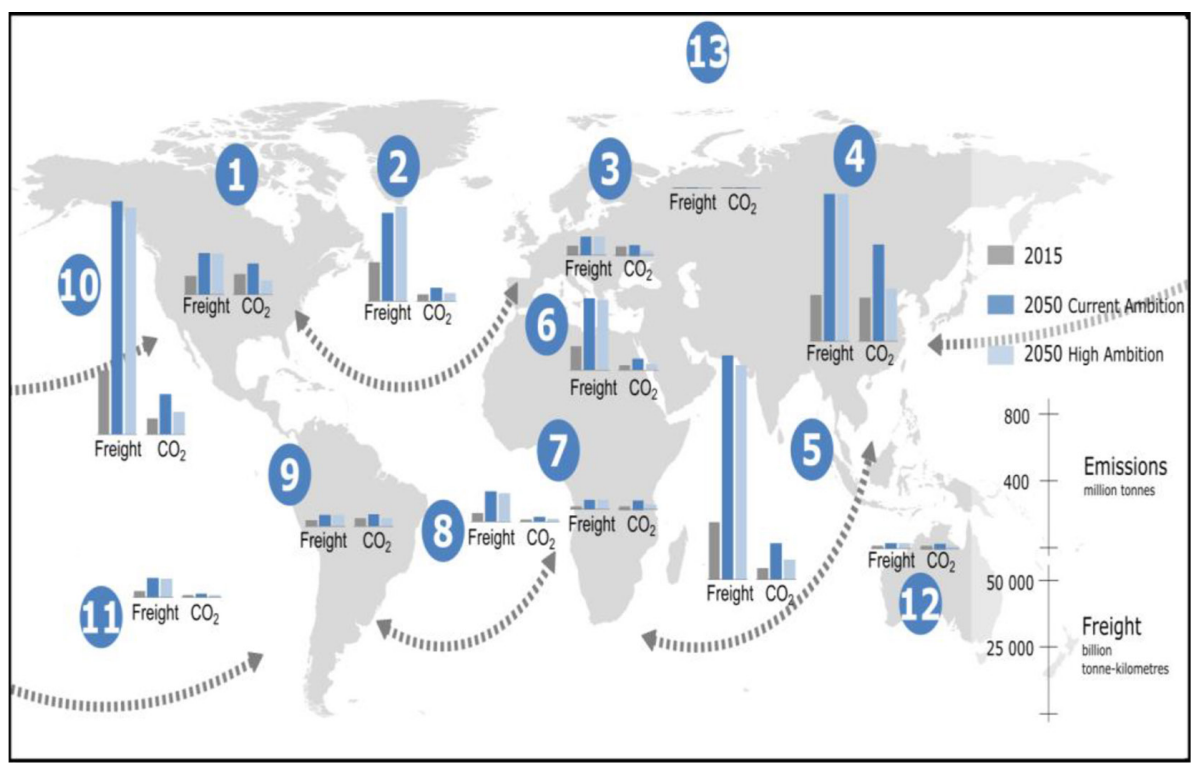

Figure 1: Global freight transport and $\mathrm{CO}_{2}$-emissions 2015-2050 (Source: [8]). Legend: 1. North America; 2. North Atlantic; 3. Europe; 4. Asia; 5. Indian Ocean; 6. Mediterranean and Caspian seas; 7. Africa; 8. South Atlantic; 9. Latin America; 10. North Pacific; 11. South Pacific; 12. Oceania; 13. Northern Sea Route 
The time horizon is set to the years 2020-2025 to allow minor adaptations of the rail infrastructure and services in the study area.

\subsection{Research set-up}

The research consisted of fact finding by means of a small literature study and conversations with a regional expert. Relevant data was added to an existing database. A case study was used to design rail service scenarios. These were modeled to estimate the fuel consumption, emissions and trip time for the respective rail. These results were then evaluated and conclusions were drawn.

\subsection{Research questions}

The main research question is: Is it possible to design rail freight routes that reduce fuel use, emissions of $\mathrm{CO}_{2}, \mathrm{NO}_{\mathrm{x}}$ and $\mathrm{PM}_{10}$, while offering competitive transport times?

The sub-research questions are the following:

- What makes a modal shift a difficult challenge for policy-makers?

- What are interesting freight routes to select for the study?

- What is an interesting example of a product to be transported via this route?

- What are the estimated fuel consumption and $\mathrm{CO}_{2}^{-}, \mathrm{NO}_{\mathrm{x}}$ - and $\mathrm{PM}_{10^{-}}$-emissions related with such services?

- Is there a time saving if an alternative route would be chosen (comparing main corridor routing with branch line routing)?

\section{THE SYSTEM AND THE PROBLEM}

\subsection{Introduction}

Global freight transport is expected to reach triple the 2015 levels by the year 2050 [8]. A doubling of transport is expected for the European Union, a [3]. This will have a sizeable impact on local emissions ( $\mathrm{NOx}$ and $\mathrm{PM}_{10}$ ) and greenhouse gas $\mathrm{CO}_{2}$ (see also Figure 1). Road and (intermodal) rail use and emissions differ substantially (Table 1). The same holds for future projections.

These figures indicate that the carbon intensity of road and rail differs significantly on a tonkm basis. The difference is smaller in practice due to:

Table 1: Freight transport and $\mathrm{CO}_{2}$-emissions by road and rail, Europe 2015-2050 (Source: [3].)

\begin{tabular}{llllll}
\hline & & & \multicolumn{2}{l}{ CO business as usual } & CO high ambition \\
& $\mathbf{2 0 1 5}$ & $\mathbf{2 0 5 0}$ & $\mathbf{2 0 1 5}$ & $\mathbf{2 0 5 0}$ & $\mathbf{2 0 5 0}$ \\
& Tonkms & Tonkms & Mton & Mton & Mton \\
\hline Road & 2819,9 & 5380,4 & 161,6 & 200,7 & 82,9 \\
Rail & 622 & 1335,4 & 2,1 & 1,3 & 0,2 \\
\hline
\end{tabular}


- Detours. The road network is much denser than the rail network and the number of intermodal terminals is also limited. This could be solved by infrastructure upgrading and better planning though;

- Use of diesel trucks in intermodal transport. Electric trucks could be used, but their payload and range is still limited, though;

- Emissions are usually stated in terms of a movement with a load factor (fill rate) back and forth. Less payload leads to higher emissions per tonkm and loss of income for the service provider. Cost of the freight service (one way) may also increase. Return payload could be organized, though;

- Freight locomotives are mainly powered by diesel or electricity. This diesel can either be conventional methanol or biomethanol. Electricity can come from mixed sources or green sources. The more green fuel is used, the lower the $\mathrm{CO}_{2}$-emissions by rail freight services.

The difference in overall emissions by road and rail is then largely explained by the different volumes transported, the fuels used, the total fuel consumption and emission factors of the fuels used to power trucks and freight locomotives.

Barge transport, the second modality in terms of volume in some European countries, is not considered in this paper.

\subsection{Policy trade-offs}

Freight transport has benefits and costs to society. Benefits include provision of goods, (direct and indirect) employment and tax income. They explain why governments and financial organisations stimulate freight transport with policy instruments like a laws and regulations, investments in infrastructure construction and maintenance [9]. The social costs of freight transport are known as transport externalities. Transport has many of these [10]. The focus will be on two categories:

- Local $\left(\mathrm{NO}_{\mathrm{x}}, \mathrm{PM}_{\mathrm{x}}\right.$, etc.) and global $\left(\mathrm{CO}_{2}\right)$ emissions to the air due to combustion of carbonbased fuels in vehicle engines. Such emissions are detrimental for nature, humans and the global climate;

- Consequences of congestion, in itself an internal effect, on main transport corridors. Congestion refers to a (too) small gap between traffic intensity I and available infrastructure capacity $\mathrm{C}$ per relevant metric (hour, day). A queing vehicle has an engine that combusts more fuel less efficient and as a consequence produces more emissions. Transport time and cost will also rise in case of congestion.

Governments are in a challenging position when balancing these social benefits and costs. Policy instruments, in particular fuel economy and emission standards, are used to stimulate technical progress. A problem arises when technical progress (a higher fuel efficiency, hence a lower fuel consumption) per (ton) km is partially neutralized by a growing number of vehicles and (ton)kms driven. Then the nett reduction in emissions will be smaller than the technically frontier allows. Additional policy effort is needed to reach the emission target.

If behaviour is the neutralizing factor, then behavioural change should be on the policy-agenda. This can take various forms, including a shift to rail. To make such a shift feasible, several success conditions have to be fulfilled. This starts with clear, transparent and feasible policy targets. For shippers and logistic companies, it should be (made) attractive to use use rail services in the areas where they are represented or do business with. 


\subsection{Modal split is fairly stable}

Today's modal split is the result of developments that took place over many decades. Many regional rail freight services were ended and railway infrastructure was closed (and removed) due to changes in manufacturing and logistics, which reduced the need for bulk transport. This left business with smaller transport volumes (up to a few wagons per time period) a choice between using trucking, leave the area or cease to exist. In most EU countries, freight transport by road has a modal share of at least $75 \%$ and it is still growing [11]. If there is potential for a modal shift, then it should be found in individual cases. The idea of a forced general (large) modal shift as promoted by the EU creates a major logistic challenge and may substantially increases transport costs for most shippers and logistic providers.

Rail is mainly focussed on bulk transport (minimum number of wagons; no single wagon load), while trucking is focussed on small volumes per trip (1-2 containers, bins, tanks). Road transport offers fast and frequent delivery at a competitive price. These requirements are hard to meet by rail. Fixed costs of rail are high. There are capacity bottlenecks and gaps in the network, which force detours and longer transport times. The only exception can be found in the main rail corridors, where transport times by road and rail are similar [12], but also there congestion is prevalent. In the European Union (EU), the TEN-T program co-finances studies and projects to "close gaps, remove bottlenecks and technical barriers, as well as to strengthen social, economic and territorial cohesion in the EU". The programme provides small subsidies for studies into and projects to improve infrastructure considered to be of supra-national importance [13].

\section{4 (Freight) transport and regional economies}

A freight service crossing a region is not necessarily benefical for that region. This holds in particular for international corridors. If the goods transported ar not (off)loaded regionally, then emissions, noise and congestion are not 'off-set' by a regional value-added. This is frequently the reason for public resistance towards (new) infrastructure and a major reason for delay of such projects [14].

Value-added could be generated when a truck or a train departs, stops or ends in the particular region. A region could stimulate this, for instance by opening or enhancing a regional intermodal freight terminal, by adding a missing link or by upgrading a regional branch of a road or rail network. Ideally, this would create a new network allowing transport from and to several destinations. Such a network could have a substantial regional-economic impact. It would help to alleviate the externalities of heavy trucks using regional and local streets, thereby improving liveability. Again, an important condition for feasibility is that shippers and railway operators adapt their logistics.

National and EU policy makers tend to favour the main TEN-T corridors, while the potential of small regional infrastructure receives much less attention. The costs of local upgrades can be limited, but their impact may be important [15]. Improved infrastructure may allow rail operators to develop attractive services. These may then help to preserve or expand regional employment and tax base, allowing pay-back of the investments made.

\subsection{Services, capacity and resilience}

The rationale for attractive regional rail services not only follows from congestion in main corridors as a consequence of growing traffic, use of terminals in corridors and the (perceived) quality of the main corridors. 
The lower density of the rail network compared to the rail network means that disruptions due to technical failures, driver malfunctions, infrastructure maintenance, accidents or natural distasters may have a bigger impact than similar disruptions would have for trucking. There are examples of incidents, which led to many months of traffic rerouting and delays [16]. Shippers are used to just-in-time services. Once these can no longer be guaranteed, second order effects will surface. Apart from damage claims, some shippers may stop using rail. A call for more resilient railways could be answered by developing and maintaining bypasses or shortcuts at the regional level.

Reducing $\mathrm{CO}_{2}$ by more rail use is challenging. International freight transport has a regional component (services start and end at some point in a region). Currently, trucks dominate regional freight transport. A key success factor for a significant and lasting shift to rail is then how to take care of the logistic needs of regional shippers and receivers of goods.

\section{METHODOLOGY}

\subsection{Assumptions}

A micro level analysis was carried out as in [4]. By understanding the micro level it is relatively straightforward and transparent to use a scale factor to simulate macro level results. The opposite approach would carry the risk that the analysis does not arrive at the micro level, hence not provide a meaningful advice to involved stakeholders.

The main actors are regional producers and suppliers of goods, logistic service providers offering road and/or rail services and relevant local and regional governments in the countries involved. They have found common ground due to the growing urgency of climate change mitigation [17]:

- Goods producers (shippers) aim to reduce their $\mathrm{CO}_{2}$-emissions per tonkm without complicating logistics or increasing operating costs;

- Rail operators optimize fuel consumption and $\mathrm{CO}_{2}$-emissions per tonkm;

- Governments stimulate rail by alleviating infrastructure bottlenecks and creating the conditions (legal, procedural, financial) that allow running of freight trains through their regions as part of a cross-border rail freight service. This support also helps to establish (not studied) regional and international passenger rail services via the same rail section(s). This may contribute to the bussiness case and lower the resistance towards (renewed) use of such trajectories.

\subsection{Scenarios and modeling}

In our previous studies simplified networks were used with two nodes - origin - destination pairs. This coarse approach does not allow precise estimations of fuel consumption and emissions of $\mathrm{CO}_{2}, \mathrm{NO}_{\mathrm{x}}$ and $\mathrm{PM}_{10}$. Many hours were spent to update an existing decision support model written in MS@ Excel@ with quite detailed routes. It allows to simulate various train parameters (freight volume, load factor, locomotive types, train length, train weight), stops and routes.

Technological parameters can be adapted if necessary to simulate technical progress. This includes engine technology, energy category (diesel, alternative), fuel consumption per tonkm, fuel specification (fuel-blend), emission factors and electricity mix (\% green) etc. 
Only tank-to-wheel emissions were considered. Fuel consumption was taken from the literature and validated by an expert. The impact of a different load factor on fuel consumption and emissions was also added to the model.

\section{CASE STUDY}

\subsection{Introduction}

It is interesting to explore the feasibility and benefits of embedding non-main corridor rail sections into a cross-border service as a means to offer attractive, fuel efficient and resilient rail freight services.

The background study included the German Saarland and Rheinland-Pfalz, the northern part of France, Luxemburg, Belgium and the Netherlands. The paper focusses on a small section of this search area.

\subsection{Node Dillingen}

Dillingen (Germany, Fig. 2) is in the heart of several European road and rail corridors, in particular Atlantic Rail Freight Corridors (RFC) 2 and 4 (Saar Railway Saarbrucken-Trier) (Fig. 3).

These corridors give access to intermodal terminals like those in Bettembourg (Luxembourg) and Dijon-Gevrey (France). An important logistic hub at Ludwigshaven (Germany) is at reasonable distance north-east of Dillingen. The area Saarbrucken-Trier-Metz-Luxembourg has a significant industrial importance. In Germany there are plants like NEMAK

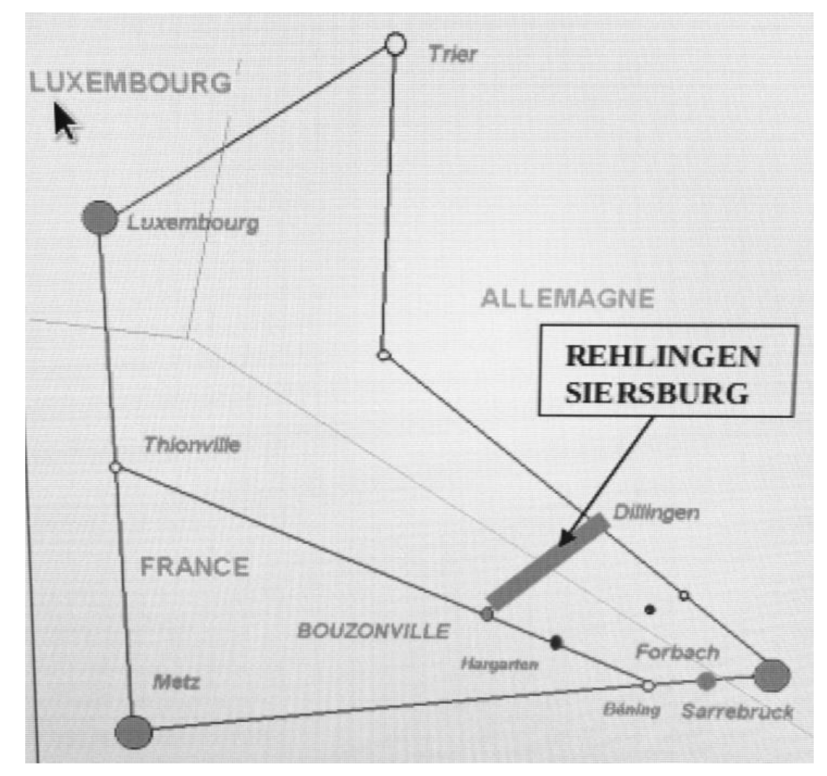

Figure 2: Node Dillingen with missing link (Source: [18]). 


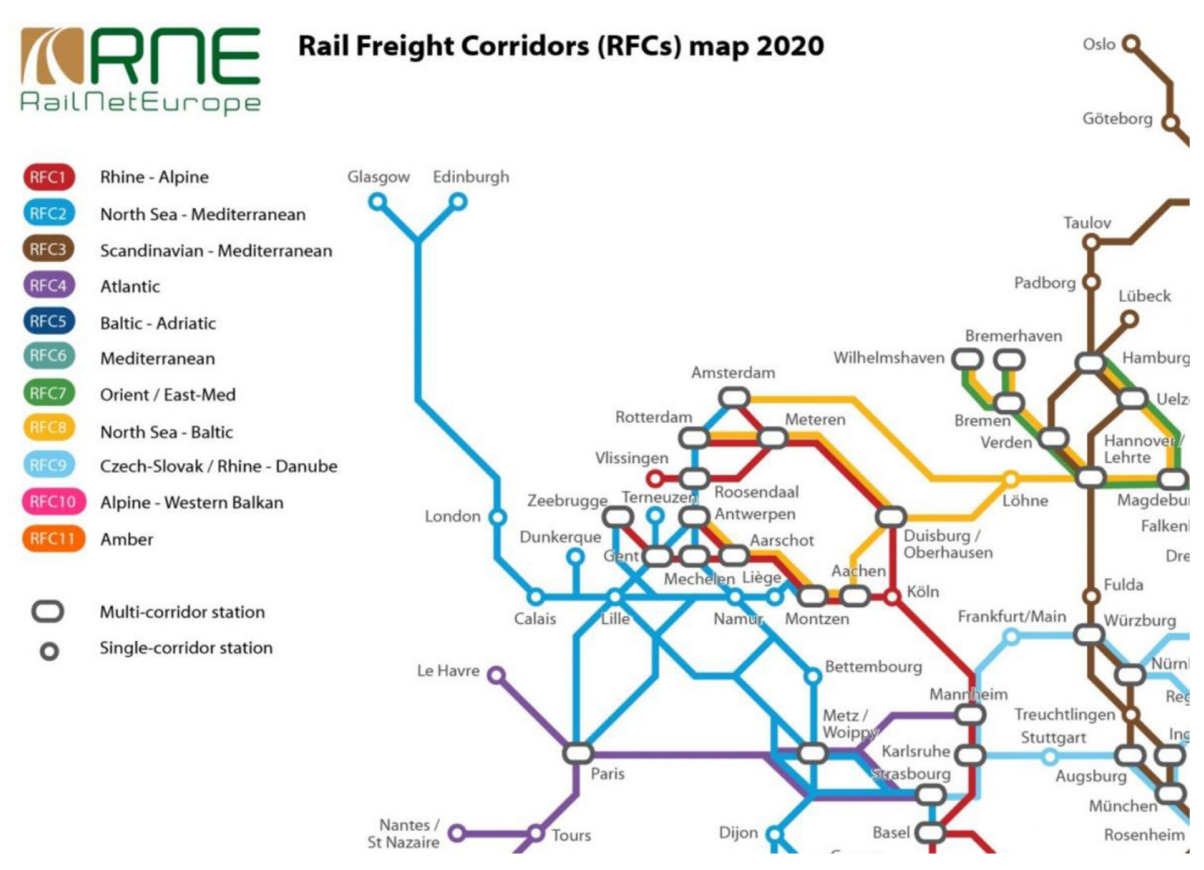

Figure 3: North-western RNE rail corridors 2020 (Source: [19]).

(aluminium), Röderberg Ford Werke (car assembly) and Dillinger Hütte (steel mill). In France there is Total Petrochemicals near Carling / Saint-Avold.

\subsection{Chalk transport}

The Dillingerhütte steel mill uses considerable amounts of chalk. This is excavated in Dugnysur-Meuse near Verdun, France. The about $7 \mathrm{~km}$ line from the quorrie to Verdun is not electrified. An average freight train has a length of 17-20 wagons and weighs between 1200 and 1500 tonnes. On flat terrain one single diesel locomotive could suffice. However, some significant slopes have to be taken. This asks for double traction; two Vossloh DE18 diesel locomotives. Their fuel consumption is in the order of 0,035 liter/tkm.

The conventional route (Table 2 ) is compared with a shortcut via the Niedtalbahn (Table 3). This should fulfill the following conditions:

- Allow the intended freight volume, train length and weight;

- Preferable reduce fuel consumption and emissions;

- Allow connections with potential shippers and receivers of bulk products.

Comparing Table 3 and 4, the Niedtalbahn option would result in a $52 \mathrm{~km}$ shorter train trip and, hence less fuel consumption and emissions. It is likely that the shorter distance also reduces trip time, but this can only be verified when the real service times (including delays and waiting at terminals) are known. 
Table 2: Route 1 - without Niedtalbahn.

\begin{tabular}{|c|c|c|c|}
\hline $\begin{array}{l}\text { Route: } \\
\text { Dugnu-sur-Meuse (F) - Verdun (F) - Conflans en } \\
\text { Jarnisy (F) - Hagondange (F) - Metz (F) - Forbach } \\
\text { (F) - Saarbrücken (G) - Dillingen (G) }\end{array}$ & & Full & Empty \\
\hline Distance in $\mathrm{km}$ & 199 & & \\
\hline Diesel fuel in ltr & & 10503 & 3490 \\
\hline $\mathrm{CO}_{2}$ in ton & & 27.83 & 9.2 \\
\hline $\mathrm{NO}_{\mathrm{x}}$ in $\mathrm{kg}$ & & 116 & 38 \\
\hline $\mathrm{PM}_{10}$ in $\mathrm{kg}$ & & 27 & 0.9 \\
\hline
\end{tabular}

Source: Own estimations

Table 3: Route 2 - with Niedtalbahn.

\begin{tabular}{|c|c|c|c|}
\hline $\begin{array}{l}\text { Route: } \\
\text { Dugny-sur-Meuse (F) - Verdun (F) - Conflans en } \\
\text { Jarnisy (F) - Hagondange (F) - Thionville (F) - } \\
\text { Bouzonville (F) - Dillingen }(\mathbf{G})\end{array}$ & & Full & Empty \\
\hline Distance in $\mathrm{km}$ & 147 & & \\
\hline Diesel fuel in ltr & & 7722 & 2565 \\
\hline $\mathrm{CO}_{2}$ in ton & & 20.5 & 6.8 \\
\hline $\mathrm{NO}_{\mathrm{x}}$ in $\mathrm{kg}$ & & 84.9 & 28.2 \\
\hline $\mathrm{PM}_{10}$ in $\mathrm{kg}$ & & 19.9 & 0.6 \\
\hline
\end{tabular}

Source: Own estimations

\subsection{Renovation of the Niedtalbahn}

Dillingen-Bouzonville was part of a strategic railway line in the German-French border area. It was inaugurated in 1901. Passenger services stopped in 1945. A service to the yearly Good Friday market in Bouzonville remains. Dillingerhüte receives trains carrying chalk and used to have outbound trains with liquid iron to France. Cross-border services stopped due to German and French decisions. Deutsche Bahn even wanted to remove a bridge, which was not granted. France does not want to pay for a local dispatcher. Rail infrastructure in France needs replacement. Deutsche Bahn renovated the German section. It is still running a passenger service until Niedaltdorf [20]. Politicians in Saarland and Bouzonville favour a reopening, but is not local politicians who decide on this, but higher level authorities, including rail network managers in both countries. Cost-benefit analyses have been carried out, but their outcome is very much dependent on the assumptions made, including dual use by passenger and freight [21].

\section{CONCLUSIONS}

The case study shows that it is possible to design (alternative) cross-border rail freight routes that significantly reduce fuel use, emissions of $\mathrm{CO}_{2}, \mathrm{NO}_{\mathrm{x}}$ and $\mathrm{PM}_{10}$. The proposed bypass 
may offer a shorter transport time and add to network resilience. A shift to rail is feasible in individual cases, but this means that the right conditions have to be created. This is particularly challenging in a case like this, because of the many stakeholders with diverging interests, the (initially) moderate to low traffic volumes and necessary investments in renewal of railway infrastructure like tracks, tunnels and signalling.

\section{ACKNOWLEDGEMENT}

We are grateful for the generous help provided by Herr Erhard Pitzius of the Plattform Mobilität SaarLorLux e.V., Überherrn, Germany. He provided us with many reports and regional information relevant for our study.

\section{REFERENCES}

[1] International Transport Forum/OECD, The Carbon Footprint of Global Trade, Tackling emissions form International Freight Transport, http://www.itf-oecd.org/sites/default/ files/docs/cop-pdf-06.pdf, Paris, 2015.

[2] Hesse, M. \& Rodrigue, J.-P., The transport geography of logistics and freight distribution, Journal of Transport Geography, 12(3), pp. 171-184, 2004. https://doi. org/10.1016/j.jtrangeo.2003.12.004

[3] European Commission, A European Strategy for Low-Emission Mobility, COM(2016) 501 final, Brussels, 20.7.2016.

[4] Bal., F. \& Vleugel, J.M., Towards more environmentally sustainable intercontinental freight transport. International Journal of Transport, Development and Integration, 4(2), pp. 129-141, 2020. Vleugel, J.M., Bal, F., Regional goods delivery: How to reduce its $\mathrm{CO}_{2}^{-}, \mathrm{NO}_{\mathrm{x}^{-}}$and $\mathrm{PM}_{10^{-}}$-emissions? International Journal of Energy Production and Management, 3(4), pp. 338-347, 2018. Janic, M., Vleugel, J.M., 2012. Estimating potential reductions in externalities from rail-road substitution in Trans-European freight transport corridors, Transportation Research. Part D: Transport \& Environment, 17(2), pp. 154-160, 2012.

[5] Chapman, L., Transport and climate change: A review. Journal of Transport Geography, 15, pp. 354-367, 2007. https://doi.org/10.1016/j.jtrangeo.2006.11.008

[6] Uddin, M. \& Huynh, N., Reliable Routing of Road-Rail Intermodal Freight under Uncertainty. Netw Spat Econ, 19, pp. 929-952, 2019. https://doi.org/10.1007/s11067018-9438-6

[7] Rodrigue, J.-P., The geography of transport systems, 5th ed., Routledge, New York, 2020.

[8] International Transport Forum/OECD, Transport Outlook 2019, http://doi.org/10.1787/ transp_outlook-en-2019-en, Paris. Accessed on: 11 April 2021.

[9] See reference 7.

[10] Demir, E., Huang, Y., Scholts, S. \& Woensel, T. van, A selected review on the negative externalities of the freight transportation: Modeling and pricing. Transportation Research Part E: Logistics and Transportation Review, 77, pp. 95-114, 2015. https:// doi.org/10.1016/j.tre.2015.02.020

[11] Pastori, E., Brambilla, M., Maffii, S., Vergnani, R., Gualandi, E. \& Dani, E., Research fro TRAN Committee - Modal shift in European transport: A way forward, research for the European Parliament, http://www.europarl.Europa.eu/RegData/etudes/ STUD/2018/629182/IPOL_STU(2018)629182_EN.pdf, retrieved May 2, 2021. 
[12] European Court of Auditors, Rail freight transport in the EU: still nog on the right track http://www.eca.europa.eu/Lists/ECADocuments/SR16_08/SR_RAIL FREIGHT EN.pdf, retrieved 18 April, 2021.

[13] European Parliament and Council, Regulation (EU) No. 1315/2013 on Union guidelines for the development of the trans-European transport network and repealing Decision No. 661/2010/EU, 2010, retrieved 5 May, 2021.

[14] NIMBY, http://en.wikipedia.org/wiki/NIMBY, retrieved 6 May, 2021.

[15] Vleugel, J. \& Bal, F., Some approaches to reduce transport time of intermodal services: Smart rail investments, European Transport $\backslash$ Trasporti Europei, 52(3), pp. 1-15, 2012.

[16] An avalanche split a hill with tracks near Kestert, Germany, along the Rotterdam-Genua corridor; the busiest in Europe. It took 1,5 months to restore the tracks. Freight and passenger trains were rerouted, delayed or cancelled. http://www.swr.de/swraktuell/rheinland-pfalz/koblenz/bahnl aerm-mittelrheintal-kestert-felsrutsch-100. html, retrieved 7 May, 2021.

[17] Rice, D., Global temperatures could pass limit set by Paris Climate deal within 5 years. www.usatoday.com/story/weather/2018/02/01/global-temperatures-could-pass-limitset-paris-climate-deal-within-5-years/1087326001, 1 February, 2018, retrieved 9 May 2021.

[18] Aubin, B., Étude « Bouzonville en train » Proposée par la Ville de Bouzonville et Bernard AUBIN, Fédération Indépendante du Rail et des Syndicats des Transports, 1998.

[19] Rail Net Europe, http://rne.eu/rail-freight-corridors, retrieved 22 May 2021.

[20] Warscheid, L., Neue Chance für Erhalt der Niedtalbahn, Saarbrücker Zeitung, 17 April 2018.

[21] Leyes, J., Wiederaufnahme eines grenzüberschreitenden Schienenverkehres über die Niedtalbahn -Analyse der Chancen und Möglichkeiten, sowie der Kosten und Nutzen, BSc thesis Hochschule Kaiserslautern, 01-02-2021. 